\title{
Strategic Planning and Branding Management of Chinese E-commerce Business: A Case Study of Three Squirrels
}

\author{
Xiyao Wang ${ }^{1, *}$ \\ ${ }^{1}$ De Montfort University-Gateway House, Leicester LE1 9BH \\ "Corresponding author.Email:P2612079@my365.dmu.ac.uk
}

\begin{abstract}
The e-commerce business in China continues to thrive. Three Squirrels (TS), one of the leaders of online food retailers, has been selected as the research object of this study. Specifically, an array of strategies adopted by TS have been reviewed and delineated, including its vision construction, technology-driven approach, internal resources management, procurement and logistic, branding and logo design, and emotional marketing strategy. Aside from the discussion of the competitive advantages of TS, some challenges faced by it have also been revealed. This case study would contribute to the management of ensuing Chinese B2C e-commerce development.
\end{abstract}

Keywords: Strategic Management, Branding Management, E-commerce Development, Three Squirrels

\section{INTRODUCTION}

With the advancement of technological innovations and applications, the volume of the e-commerce industry in China has been increasing in the past decade. The great advantages brought by the e-commerce, such as the discounted price, enhanced convenience, and diversified marketing and promotional methods, attract millions of Chinese consumers to shop online [1]. In this context, numerous emerging e-commerce players have entered this arena, among which Three Squirrels (TS) is one of the largest and most successful Chinese local food e-commerce enterprises, with more than 10-billion sales in 2020 [2].

As a brief introduction, TS was co-founded by Liaoyuan Zhang and four partners in Wuhu City, Anhui Province, China, in 2012. For now, the headquarter of the company is still based in Wuhu, with more than 4,000 permanent employees. The main products sold by TS include but not limited to nuts, preserved meat, dried fruit, puffed snacks, and other full range of leisure food [2]. In addition, it also has peripheral products such as cultural and creative gifts. TS has been successfully listed on the Shenzhen Stock Exchange in 2019 [2].

Fundamentally, the strategic positioning and branding management of TS has enabled this company to keep thriving in the current economic situations and fierce market competition. In this review article, an array of strategies that contribute to the success of TS are comprehensively discussed, comprised of its vision construction, technology-driven operation, procurement and logistic processes, branding tactics, as well as emotional marketing strategies. Consequently, it can be said that the coordination of all these strategic procedures has enabled TS to be successful in the Chinese e-commerce market.

Despite its huge success, TS has also encountered massive dynamics and uncertainties due to the everchanging market environments and the recent outbreak of COVID-19. Therefore, this study, not only discusses the success factors of TS, but also analyzes what factors would create potential challenges in the development process of TS. As a result, relevant suggestions are put forward in order to contribute to the future development for both TS and other similar B2C e-commerce and eretailing enterprises in China.

\section{VISION AND CORE VALUES OF THREE SQUIRRELS}

"Vision" is a joint belief that has been formed by organizational leaders to deliver the organization's core values and imaginary future [3]. Through the vision statements, all members of the organization can be effectively cultivated and encouraged to realize the 
aspired future scenario and correlated missions and objectives of the organization [3]. Fundamentally, for an enterprise, the vision is paramount to enable it can excel in the contemporary increasingly competitive market environment. Accordingly, the management processes laid by the organization should also be in line with the vision and then strive to ensure the vision can be attained.

The vision statements of TS are three sentences: 1) live for 100 years; 2) entering the Global 500 and 3) serving the vast majority of families in the world [2]. In accordance with these visions, TS also has a customeroriented core value. An array of strategic planning and management practices have been implemented aligning with this core value to ensure brilliant customer services can be achieved. With regard to this aspect, TS has a belief that customers are critical to the success of the enterprise and believes that customers would prefer those businesses that can listen to their complaints and firmly adhere to the service guarantee.

Customer-orientated values are significant for nowadays business enterprises in terms of retaining customers and increasing their competency levels; conversely, any poor performance in customer relations leads to stiff operation and decreased customer trust and loyalty. Based on previous studies, TS can be said as a successful case that enables its strategic capabilities are constructive to its vision and that can correctly spend its resources in the right places, such as in the domain of human resources and other customer relationship-related activities [4].

Also, TS has been considered as a successful enterprise that has made its visionary strategies can be implemented vertically from the bottom level to top positions and ensure all service personnel can react as central connectors with consumers [4]. Moreover, the management layout of TS has enhanced the organizational ability to breakthrough market shares as managers and leaders of TS are highly skilled in consumer relationships [5]. Resultantly, these practices of TS have significantly improved the overall organizational decision-making process of keys issues like solving customers' complaints related to delays in delivery of products ordered.

Nonetheless, other than its customer-oriented vision and core values, there are also a set of specific strategies that attribute to its success, including its procurement and logistic procedure, adoption of technologies, and branding and marketing strategies, which would be discussed in the following.

\section{TECHNOLOGY-DRIVEN STRATEGY OF THREE SQUIRRELS}

Technical strategies are becoming more and more critical in ensuring e-commerce business enterprises can thrive in a competing environment [6]. E-commerce enterprises are greatly facilitated by technological advancement that can enhance their productivity levels and competitive capabilities. Thus, only those organizations that can adapt to the technological driving forces would have high chances of success in the market. In the case of TS, it has been constantly undergoing the maintenance and improvement of its portfolio and technological applications.

$\mathrm{TS}$, as an e-commerce enterprise, is a representative business case that shows how adopting multiple innovative channels to reach customers, such means as personal sales, online sales, and roadshows [4]. For instance, TS uses the internet and social media such as WeChat, TikTok to provide customers with a more convenient experience to buy its products and promote its brands. Additionally, TS also concentrates on traditional online shopping websites such as Alibaba's TMall and JD.com. Besides, personal selling is used to reach those customers who are within their surroundings. Last but not least, TS also holds roadshows in major cities of China to enhance its market exposure.

Other than the promotional channel, TS also uses technology to research market trends that can impact their operations positively [5]. In detail, technology is used to collect customer and brand-related information, and then all these data would be used for research and the following market communications purposes. For instance, relevant promotion information can be sent to its customers in time to keep them updated on changes in the products and prices.

Moreover, TS has developed its intranet to improve customer service satisfaction in online sales [5]. With the arrival of the big data era, TS would accommodate and conduct a variety of decision-making processes through information technology systems, which has helped TS to better analyze the behavioral characteristics and product preferences from all types of customers. Finally, to ensure progressive improvement in customer experience, TS has recently set up a special department to develop an ERP system that will be used for timely information processing in the future.

\section{PROCUREMENT AND LOGISTIC OF THREE SQUIRRELS}

Procurement and purchasing are the core business activities for e-commerce business [6]. Common purchasing strategies include a set of decision-making tasks with respect to aggregation, standardization, category management, and relationship management. TS acquires its production materials from nature and sticks to its high food quality, leaving the customers a brand image of "being healthy", especially compared to other chemically produced food products [2]. In spite of the high food quality, the cost for acquiring the materials is 
comparatively cheaper. This is because TS would prefer to make their procurement in large volume and always make payments to suppliers on time. This credibility and trustworthiness enable TS to obtain competitive advantages in procurement.

The logistics of TS features in its intelligent logistics warehousing. For instance, the smart storage control of the TS warehouse makes the products safe and secure from germs [2]. Meanwhile, based on the real-time management of inventory and shipping, the products will never be overstocked, and the freshness can be maintained. To date, TS has constructed three storage centers in China and has been developing an information system to improve the interconnections among the three storage centers [4]. As a consequence, all these efforts in logistic management have shortened the supply chain and enhanced the delivery speed. For now, TS can guarantee that all the orders received in the morning can be delivered within one day in major Chinese cities [2].

\section{BRANDING AND LOGO DESIGN OF THREE SQUIRRELS}

Branding is the strategic process of changing those intangible product elements and features to obtain competitive advantages [7]. The intangible assets of TS have greatly enhanced its market exposure and competitiveness level. Among all the branding tactics, a brand logo is one of the most crucial elements to deliver the values of a brand.

The brand logo represents one of the most paramount visual constitutions of a brand [8]. Business organizations use a brand logo to outdo their competitors and stand out in the market. Some considerations included in the designing process of a logo comprise the choice of color, shape, form, tag lines, style consistency, and other visual elements. TS has been focusing on the visual appeal of product development and packaging design. As shown in Figure 1 , the logo of TS influences customers' perceptions through the presence of cartoons.

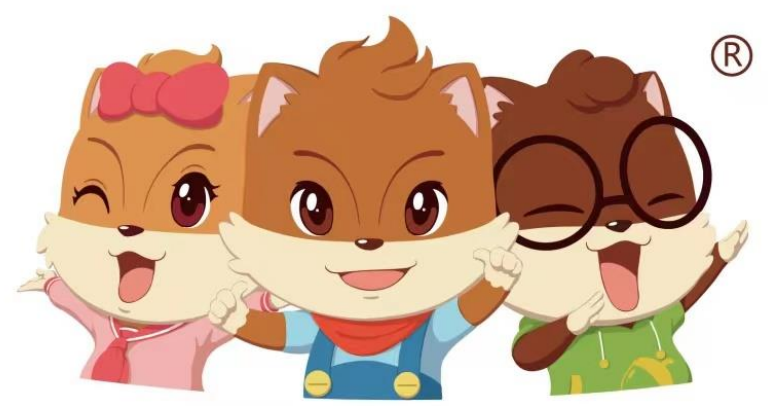

Figure 1 Brand Logo

In detail, the brand logo of TS is three lovely and little squirrels. Each squirrel has its name, and each word represents a typical character. The design of the brand logo of TS is anthropomorphized, and this special design of the logo aims to leave the customers a friendly and easy-going brand image [5]. This logo has been massively and widely used in product packaging, promotion, giving customers memorable visual experiences. For now, this brand logo has even become an IP that has been used to produce squirrel cartoons, comics, and squirrels' big films, which have kept positively influencing customers nationally and globally.

\section{INTERNAL RESOURCES MANAGEMENT OF THREE SQUIRRELS}

Internal resources management refers to how an enterprise views and harnesses its inner strengths [8]. As for the TS, it is very good at applying its capital advantages, which is considered to be another competitive advantage of TS. In general, capital advantages occur where an organization has a higher output than inputs [7]. Consequently, organizations with a large base of customers have capital advantages. TS has entered into numerous marketing in China and recently has expanded its market internationally. Thus, the vast sales volume makes TS have a capital benefit over other organizations. For instance, in 2018, Three Squirrels net income was $40 \%$ higher than the previous year, meaning the capital advantage of the enterprise is more elevated [4]. The capital advantage has in turn enabled TS to put more financial resources into enhancing customer experience.

Aside from cash flow and capital management, TS is also a master in talents and human resources management. Talent advantages benefit any organization aiming to have a competitive image and attain substantial market shares [7]. Specifically, TS has a very high standard in recruitment. For instance, TS would hire talents globally, which has enabled it to recruit highly specialized executives and skilled and experienced employees worldwide. Especially, people who specialize in information technologies have been massively hired. Resultantly, the talent advantage of TS has made it the most significant and successful B2C enterprise in China [5].

\section{EMOTIONAL MARKETING OF THREE SQUIRRELS}

Emotional marketing strategies refer to focus more on the customers' emotions and spiritual enjoyment during the marketing and promotion practices, as consumers always favor those products which are designed and developed in line with customers' emotional needs [8]. Emotional marketing is a very effective way to enhance the loyalty and trust of the consumers to the company through meeting the emotional needs of consumers [7]. 
In this aspect, TS focuses on creating emotional connections and interactions with consumers and make the brand become an emotionally attached business. For instance, TS has created the so-called "Squirrels Shopping Experience" that has established a highstandard service guarantee lasting from pre-selling to after-sales service. Additionally, the excellent anthropomorphic communication has made customers feel easy-going and being welcomed.

\section{CHALLENGES FACED BY THREE SQUIRRELS AND RECOMMENDATIONS}

As a sum of the above analysis, it can be found that TS has achieved competitive advantages by formulating and implementing a variety of innovative operational strategies. All these strategies have allowed TS to survive and boom even in the current context negatively affected by the covid-19 pandemic and economic crisis. Nevertheless, TS has also been experiencing challenges within and outside the organization.

As discussed by previous studies, the major challenges faced by TS are caused by the scale of its business such as lacking innovations for products and focusing too much on revue performance [4][5]. More specifically, TS has enlarged its product line to a multiplex food typology. Thereby, it becomes increasingly difficult for TS to keep putting out new and innovative ideas and product design. Some customers have criticized that TS has copied a lot of ideas from its competitors, making it gradually losses its innovative DNA. In the meantime, as food retailing is an easy-toimitate industry, if TS does not upgrade its product line from time to time, its competitors would catch up with them in a very short time period, which may cause customer disloyalty with TS.

Besides, although TS focuses very much on ensuring customer experience and satisfaction, the massive scale production process of TS has now led to growing quality problems as some resources now have to rely on outside suppliers. All of these can lead to the risky quality issue that would ultimately cause a decreased consumer loyalty and trust level. Therefore, more burdens have been put onto TS, calling for stricter speculative supervision and inspection of the final product.

As for some recommendations for the ensuing development of TS and other similar B2C e-commerce businesses, it is suggested that their management team has to comprehensively assess their strengths, weaknesses, opportunities, and threats. First, the organization should always keep an eye on those opportunities that are available from the external and internal environment, such as technological advancements, and new social-cultural trends, so on and so forth.
Other than evaluating those advantages, threats and challenges, whether internal or external, should be monitored instantly. For instance, the current unstable COVID factors, the threats from all-around competitors, etc. should be carefully examined and prepared in advance. Only in this way, the future development of B2C e-commerce can be prospective and keep generating new motives to attract and meet the needs of the ever-changing market profile.

\section{CONCLUSION}

Generally, SWOT analysis is essential in ensuring business organizations thrive in a competitive environment. Ideally, SWOT analysis enables organizations to evaluate their strengths within the business like strategic vision and management layout of the organization and production process management. Additionally, organizations have to assess their weaknesses, such as their production method management, leading to inferior quality products. For instance, their common weaknesses of Three Squirrels Company were on lack of innovation and upgrading strategies that their competitors cannot imitate and cause customer disloyalty with Three Squirrels. Besides, the organization evaluates the opportunities available from the external and internal environment, such as technological advancement, technical and structure improvement, etc. For example, Three Squirrels has used options such as ensuring they are first adapting to technological changes and improving their technical system through a managed approach. Nonetheless, threats are the external forces that a business experiences on its operations, such as stiff competition, lack of internet and customer retention strategies, and lack of market share. Three Squirrels experiences business threats such as competition from other ecommerce food producers that imitate its innovative approach to fit in the marketplace and lure strong consumers of Three Squirrels products. Consequently, Three Squirrels has some strength that has ensured it continues being the best online food producer like having qualified staffs who have high customer relation and goods branding strategies like their Logo and brand name. This has continued to be their best strength in safeguarding their competitive image within and outside China. Furthermore, Three Squirrels are experiencing another threat of production as they rely on outside displays to cause quality issues of their products. Therefore, to cope with the threats, the enterprise is recently developing its production industry and recruiting high specialized executives and human resources to keep innovation that cannot be counterfeit at high levels.

\section{REFERENCES}

[1] Zhang, Y.Y., Q. Zheng, and H. Wang, Challenges 
and Opportunities Facing the Chinese Economy in the New Decade: Epidemics, Food, Labor, ECommerce, and Trade. The Chinese Economy, 2021: p. 1-3.

[2] Three Squirrels. About Us. n.d.; Available from: http://www.3songshu.com/about-us.html

[3] Goldberg, B., \& Sifonis, J. G. (1998). Focusing your e-commerce vision. Management Review, 87(8), 48-52.

[4] Yan, H. E. (2018). Study on Offline Marketing Strategy of Three Squirrels E-Commerce Company. Journal of Chengdu Normal University.

[5] Wang, Y., Chen, Y., Jiang, K., \& Chang, Y. (2020). The Application of AHP in Enterprise Site Selection--Taking Three Squirrels as an Example. Academic Journal of Business \& Management,
2(6), 128-134.

[6] Gao, L., Kim, G. J., \& Kim, H. H. (2019). A Study on the Evaluation of Operational Efficiency of ECommerce Demonstration Enterprise in China. Journal of Digital Convergence, 17(12), 181-190.

[7] Illani, I. (2018). Transform Customer Experience: How to achieve customer success and create exceptional CX. John Wiley \& Sons

[8] Fouskas, K., Pachni-Tsitiridou, O., \& Chatziharistou, C. (2020). A Systematic Literature Review on E-Commerce Success Factors. Strategic Innovative Marketing and Tourism, 687-694. 